NBER WORKING PAPER SERIES

\title{
STUDENT SORTING AND BIAS IN VALUE ADDED ESTIMATION: SELECTION ON OBSERVABLES AND UNOBSERVABLES
}

\author{
Jesse Rothstein \\ Working Paper 14666 \\ http://www.nber.org/papers/w14666
NATIONAL BUREAU OF ECONOMIC RESEARCH
1050 Massachusetts Avenue
Cambridge, MA 02138
January 2009

I thank Nathan Wozny and Enkeleda Gjeci for research assistance. I am grateful to the North Carolina Education Data Research Center and the North Carolina Department of Public Instruction for assembling and making available the data used in this study. This work has benefited from helpful conversations with Jane Cooley, Gordon Dahl, Ed Glaeser, Brian Jacob, David Lee, and Diane Schanzenbach, and from comments from an anonymous referee. Financial support was generously provided by the Industrial Relations Section and the Center for Economic Policy Studies at Princeton and by the U.S. Department of Education (\#R305A080560). The views expressed herein are those of the author(s) and do not necessarily reflect the views of the National Bureau of Economic Research.

NBER working papers are circulated for discussion and comment purposes. They have not been peerreviewed or been subject to the review by the NBER Board of Directors that accompanies official NBER publications.

(C) 2009 by Jesse Rothstein. All rights reserved. Short sections of text, not to exceed two paragraphs, may be quoted without explicit permission provided that full credit, including $\odot$ notice, is given to the source. 
Student sorting and bias in value added estimation: Selection on observables and unobservables Jesse Rothstein

NBER Working Paper No. 14666

January 2009

JEL No. C12,C52,I21,J33,J45

\begin{abstract}
$\underline{\text { ABSTRACT }}$
Non-random assignment of students to teachers can bias value added estimates of teachers' causal effects. Rothstein $(2008 \mathrm{a}, \mathrm{b})$ shows that typical value added models indicate large counter-factual effects of 5th grade teachers on students' 4th grade learning, indicating that classroom assignments are far from random. This paper quantifies the resulting biases in estimates of 5th grade teachers' causal effects from several value added models, under varying assumptions about the assignment process. If assignments are assumed to depend only on observables, the most commonly used specifications are subject to important bias but other feasible specifications are nearly free of bias. I also consider the case where assignments depend on unobserved variables. I use the across-classroom variance of observables to calibrate several models of the sorting process. Results indicate that even the best feasible value added models may be substantially biased, with the magnitude of the bias depending on the amount of information available for use in classroom assignments.
\end{abstract}

Jesse Rothstein

Woodrow Wilson School of Public and International Affairs

and Department of Economics

Princeton University

Industrial Relations Section

Firestone Library

Princeton, NJ 08544

and NBER

jrothst@princeton.edu 


\title{
Student sorting and bias in value added estimation:
}

\author{
Selection on observables and unobservables
}

\author{
Jesse Rothstein ${ }^{*}$ \\ Princeton University and NBER
}

January 11, 2009

\section{Abstract}

Non-random assignment of students to teachers can bias value added estimates of teachers' causal effects. Rothstein (2008a, b) shows that typical value added models indicate large counter-factual effects of 5th grade teachers on students' 4th grade learning, indicating that classroom assignments are far from random. This paper quantifies the resulting biases in estimates of 5th grade teachers' causal effects from several value added models, under varying assumptions about the assignment process. If assignments are assumed to depend only on observables, the most commonly used specifications are subject to important bias but other feasible specifications are nearly free of bias. I also consider the case where assignments depend on unobserved variables. I use the across-classroom variance of observables to calibrate several models of the sorting process. Results indicate that even the best feasible value added models may be substantially biased, with the magnitude of the bias depending on the amount of information available for use in classroom assignments.

\footnotetext{
* Industrial Relations Section, Firestone Library, Princeton NJ 08544. jrothst@princeton.edu. I thank Nathan Wozny and Enkeleda Gjeci for research assistance. I am grateful to the North Carolina Education Data Research Center and the North Carolina Department of Public Instruction for assembling and making available the data used in this study. This work has benefited from helpful conversations with Jane Cooley, Gordon Dahl, Ed Glaeser, Brian Jacob, David Lee, and Diane Schanzenbach, and from comments from an anonymous referee. Financial support was generously provided by the Industrial Relations Section and the Center for Economic Policy Studies at Princeton and by the U.S. Department of Education (\#R305A080560).
} 


\section{Introduction}

Proposals to consider teacher quality in hiring, compensation, and retention require adequate measures of quality. This is increasingly defined in terms of educational outputs, as reflected in student performance, rather than by teacher inputs like graduate degrees and experience. In order for output-based quality measures to be of use, they must reflect teachers' causal effects on the student outcomes of interest, not pre-existing differences among students for which the teacher cannot be given credit or blame.

If students were known to be randomly assigned to teachers, there would be no systematic differences in students' potential outcomes across teachers, so straightforward comparisons of mean end-of-year achievement would provide unbiased estimates of teachers' effects. ${ }^{1}$ But there are many reasons for teachers not to be randomly assigned. Principals may attempt to group students of similar ability together, so as to permit more focused teaching to students' skill levels, or they may try to spread high- and low-ability students across classrooms. Teachers who are thought to be particularly skilled at teaching, e.g., reading skills may be assigned students who are in need of extra reading help. Students who are known to create trouble together may be intentionally assigned to different classrooms. Teachers who the principal would like to reward may be given the easiest-to-teach students, with troublemakers assigned to disfavored teachers in an effort to drive them away. ${ }^{2}$ Finally, parents, perceiving teacher assignments as important determinants of their children's success, may intervene to ensure that their students are given a favored teacher or kept away from a disfavored one.

Given non-random assignments, the evaluation challenge in teacher effect modeling is to distinguish teachers' causal effects from the effects of pre-existing differences between the students in their classrooms. If the determinants of classroom assignments are not adequately controlled, teacher effect estimates will be biased. This bias is not averaged away even in large

\footnotetext{
${ }^{1}$ There would still be the problem of accounting for sampling variation in the estimates: Because each teacher is in contact with only a few dozen students per year, annual estimates of teacher effects are quite noisy, and compensation schemes based on these estimates would have to be robust to the misidentification of teacher quality that results from this noise. But existing strategies - e.g., the Empirical Bayes approach used by Kane and Staiger (2008) or the similar Best Linear Unbiased Predictor used by the Tennessee Value Added Assessment System (Sanders and Horn, 1994) - suggest methods for doing this.

2 This aspect of assignments is likely to depend on the accountability metric in place: If teachers are rewarded for their value added and if value added estimates can be biased by systematic student assignment, the pattern of assignments is likely to change so that favored teachers benefit from this bias and disfavored ones are penalized.
} 
samples, and existing methods for adjusting estimates for sampling error will not in general remove its effects from teacher rankings.

The premise of "value added" models is that differences in the difficulty of the task faced can be controlled by holding teachers responsible for students' gains over the course of the year rather than for their absolute end-of- year achievement levels. Rothstein (2008a, b) shows that this is false. Students are sorted across classrooms in ways that correlated with both their score levels and their gains. Specifically, 4th grade gains are highly non-randomly sorted across 5th grade classrooms, with nearly as much across-class variation as in 5 th grade gains. Because annual achievement tends to revert quickly toward a student-specific mean, a student with a 4 th grade gain that exceeds the average by one standard deviation (SD) can be expected to fall short of the average in 5 th grade by about 0.4 SDs. Existing value added models attribute this shortfall to the 5th grade teacher. A teacher assigned students with high 4th grade gains in the previous year will look like a bad teacher through no fault of her own, while a teacher whose students posted poor gains in the previous year will be credited for their predictable reversion to trend.

Although Rothstein (2008a, b) documents substantial non-randomness in teacher assignments that violates the restriction of common value added models (hereafter, VAMs), he does not directly estimate the magnitude of the resulting biases, and he provides little evidence about the prospects for correcting them via more sophisticated controls for students' past achievement trends. ${ }^{3}$

This paper attempts to quantify the bias created by non-random assignment in several value added specifications. Three conditions govern the bias. It depends first on the amount of information available for use in the classroom assignment process about students' potential endof-year achievement or annual gain, second on the importance attached to this information in assignments, and third on the degree to which the control variables included in the value added specification can absorb the information used in assignments.

Value added studies frequently distinguish between the effect of having a particular teacher and the effect of being in a particular classroom, with the former included in the latter. I take the classroom effect - the causal effect of being in one classroom as opposed to another in

\footnotetext{
${ }^{3}$ Rothstein (2008a, b) does demonstrate that unbiased estimation requires controls for dynamic student achievement: Teacher assignments are not governed solely by permanent student characteristics, but respond dynamically to each year's test scores. This rules out fixed effects solutions like those used by Harris and Sass (2006); Koedel and Betts (2007); Jacob and Lefgren (2008); Rivkin et al. (2005); and Boyd et al. (2008).
} 
the same school - as the parameter of interest. ${ }^{4}$ This avoids the problem of distinguishing different components of the classroom effect, the most obvious being the effects of teacher quality and of peers. This problem is complex even when classroom assignments are random and is much more so with non-random assignments. But the identification of classroom effects is a necessary precondition for the larger problem of isolating teachers' causal effects, and by focusing on this smaller, first problem I can place a lower bound on the bias in estimates of teachers' effects that is produced by the assignment process.

I distinguish between two forms of non-random assignments: Those that depend only on variables which are observed by the analyst, with random assignment conditional on those, and those that depend as well on information known to participants in the assignment process but not observed by the researcher. In the former case, "selection on observables," bias in classroom effect estimates can be measured directly. In the latter, the magnitude of the bias can be quantified only with assumptions about the amount and nature of information that is used in classroom assignments. I take an approach that is in the spirit of Altonji, Elder, and Taber's (2005; hereafter $A E T$ ) assumption that sorting on unobserved variables resembles sorting on observables, though the specific assumptions differ: Where AET assume that sorting is incidental and is equally correlated with observed and unobserved determinants of the outcome variable of interest, I assume that the sorting is intentional and that it depends on a limited set of predictors that are observed by the school principal, ${ }^{5}$ a subset of which are observed by the researcher as well. AET's assumption represents a limiting case for my analysis, in which the principal can perfectly predict students' end-of-year achievement and gains before making teacher assignments. I also consider several more plausible scenarios for the principal's role in assignments.

Section 2 describes the data. In Section 3, I demonstrate that past test scores and behavioral variables are strongly predictive of future achievement and achievement gains. Section 4 summarizes the evidence from Rothstein $(2008 \mathrm{a}, \mathrm{b})$ that teacher assignments are

\footnotetext{
${ }^{4}$ If a teacher's assignments are uncorrelated across cohorts - that is, if a teacher who gets high-potential-gain students this year is no more or less likely than any other teacher to get high-potential-gain students next year - then studies that examine several cohorts of students for the same teacher can convert bias in the classroom effect into mere sampling error in the teacher's effect. But this uncorrelated assignments assumption is a strong one, and it does not appear to hold - even approximately - in the North Carolina data used here.

${ }^{5}$ For simplicity, I discuss class assignments as the outcome of principals' decisions. This is not meant to restrict the principal to be the only determinant of these assignments; the principal's decision might reflect input from parents, teachers, and the student itself.
} 
importantly correlated with past scores. In Section 5, I examine the bias that arises in several common value added models if classroom assignments are random conditional on the observed variables. Section 6 describes the methodology for assessing the bias that arises if parents and principals have more information about students' potential learning growth than is available in research data sets. Section 7 presents the results of the analysis of selection on unobservables. Section 8 concludes.

\section{Data}

I work with longitudinal administrative data on students in public elementary schools in North Carolina, assembled and distributed by the North Carolina Education Research Data Center. North Carolina has been a leader in the development of linked longitudinal data on student achievement, and the North Carolina data have been used for several previous value added analyses (Clotfelter, Ladd, and Vigdor 2006; Goldhaber 2007). ${ }^{6}$

I focus on the value added of 5 th grade teachers in 2000-2001. I use annual end-of-year tests that were given in grades 3-5, as well as "pre-tests" given at the beginning of grade 3 . The tests purport to use a "developmental" scale, and the score scale is intended to be meaningful (i.e. scores are cardinal and not simply ordinal measures) both across grades and across the distribution within grades. ${ }^{7}$ I standardize scores so that the population mean is zero and the standard deviation one in 3rd grade; by using the same standardization in all grades I preserve the comparability of scores across grades.

The North Carolina data do not identify students' teachers directly, but they do identify the person who administered the end-of-grade tests. In the elementary grades, this was usually the regular teacher. I follow Clotfelter, Ladd, and Vigdor (2006) in using a linked personnel database to identify test administrators with regular teaching assignments. I count a match as valid if the test administrator taught a self-contained (all day, all subject) 5th grade class that was not coded as Special Education or Honors and if at least half of the tests that she administered

\footnotetext{
${ }^{6}$ North Carolina was one of the first two states approved by the U.S. Department of Education to use "growthbased" accountability models in place of the status-based metrics that are otherwise required under No Child Left Behind.

${ }^{7}$ It is not clear that a scale with this property is even possible (Martineau, 2006), or even if it is how one would know whether a test's scale has the property. Nevertheless, value added modeling as typically practiced is difficult to justify if scores are not interval scaled both across and within grades. See Ballou (2002) and Yen (1986). The analysis here is not sensitive to violations of this property, though if it does not hold the value added estimators considered (here, and elsewhere in the literature) are difficult to justify. See Rothstein (2008a).
} 
were to 5 th grade students. $73 \%$ of 5 th grade tests were administered by teachers who are valid by this definition.

My analysis focuses reading scores, though similar results obtain for math scores. My sample consists of students who were in 5th grade in 2000-2001, who had a valid teacher assignment in that year, and for whom I have complete test score data in grades 3-5. Table 1A presents summary statistics and a correlation table for reading scores on the 3rd grade pretest and on the end-of-grade tests in 3rd, 4th, and 5th grades, as well as for the 5th grade gain score (defined as the difference between the 4th and 5th grade scores). Mean scores in my completedata sample are about 0.07 standard deviations higher than in the population in every grade. Scores are correlated about 0.80 in adjacent grades (lower for the 3rd grade pre-test, which is substantially shorter), with slightly reduced correlations across longer time spans. 5 th grade gains are weakly positively correlated $(+0.07)$ with 5 th grade score levels and strongly negatively correlated (-0.52) with 4th grade scores. They are notably negatively correlated $(-0.25)$ with 3 rd grade scores as well.

Observed scores are noisy measures of true achievement. The degree of measurement error in test scores is usually measured by the "test-retest reliability," the correlation between students' scores on alternative forms of the same test administered a short interval apart. ${ }^{8}$ A 1996 report estimates that the test-retest reliability of the North Carolina 7 th grade reading test is 0.86 (Sanford 1996, p. 45). Unfortunately, test-retest studies have not been conducted for other grades. Under the assumption that individual item reliability is constant across grades and that item responses are independent, the 7th grade reliability can be extended to the shorter tests in earlier grades. ${ }^{9}$ Doing so, I estimate that the grade- 3 pre-test has reliability 0.72 , the grade- 3 endof-grade test has reliability 0.84 , and the tests in grades 4 and 5 have reliability 0.86 . I treat these as known, without sampling error. ${ }^{10}$

\footnotetext{
${ }^{8}$ Test makers often report alternative measures of reliability, e.g. internal consistency measures that are based on correlations between a student's scores on different subsets of questions. The internal-consistency reliabilities for the tests in grades 3, 4, and 5, respectively, are 0.92, 0.94, and 0.93 (Sanford, 1996, p. 45). The corresponding statistic for the grade-3 pre-test used for the cohort under consideration is not reported, but a more recent form of the test has reliability 0.82 (as compared with 0.92 in on the corresponding tests in grades 3-5; see Bazemore, 2004, p. 63). These statistics are computed under the assumption that responses are independent across questions; common shocks (e.g. a cold on test day) would lead these methods to overstate the test's reliability.

${ }^{9}$ If item responses are not independent, reliability will be less sensitive to test length, and I will most likely understate the reliability of the (relatively short) 3 rd grade pretest.

${ }^{10}$ The sample for the test-retest study was only 70 students, in 3 classrooms. If the 70 observations are independent, an approximate confidence interval for the grade- 7 test reliability is $(0.78,0.91)$, though within-classroom
} 
A known reliability allows me to compute summary statistics for true achievement, net of measurement error, assuming that errors are independent across grades. These are reported in Table 1B. The correlation between a student's true achievement in adjacent grades is approximately 0.96 . The 5 th grade gain is strongly negatively correlated with achievement levels in all grades.

One can examine across-grade correlations in gain scores as well as in score levels. The correlation between observed grade-4 and grade-5 gains is -0.42 . Measurement error in the annual test scores biases this downward, but even when corrected the correlation remains negative. Thus, students with above-average gains in grade 4 will, on average, have belowaverage gains the following year. To the extent that such students are systematically assigned to particular teachers, value added models that fail to account for this mean reversion will be biased against those teachers.

\section{Predictions of grade 5 achievement and gains}

The relevance of classroom assignments for value added estimation depends crucially on the degree to which students' gains are predictable based on prior information. If 4th grade characteristics are entirely unpredictive of 5 th grade gains, then even assignment on the basis of those characteristics will not create bias in 5th grade value added models. Table 2 presents several specifications for students' reading scores at the end of grade 5, using prior scores and other predetermined variables as explanatory variables. Because it is almost certainly more difficult to control for the sorting of students across schools than within, and because I focus in this paper in identifying differences in teachers' effects within schools, I consider only specifications for within-school variation in 5th grade scores. The first column shows that $87 \%$ of the variance in 5th grade scores is within schools. Column 2 adds the 4 th grade reading score. This has a coefficient of 0.680 ; neither zero nor one is within the confidence interval. The inclusion of the 4 th grade score increases the model's $R^{2}$ by $0.55 ; 4$ th grade scores explain $63.5 \%$ of the within-school variation in 5th grade scores.

Column 3 adds to the specification reading scores from the beginning and end of grade 3 . Both are significant predictors of 5 th grade scores. Their inclusion lowers the 4 th grade score

dependence would imply a wider interval. Note also that a given test will have higher reliability in a heterogeneous population than in a homogeneous one. The likely homogeneity of the test-retest sample suggests that the reliability in the population of North Carolina students is probably higher than was indicated. 
coefficient by about one third, and raises the within-school $R^{2}$ by 0.045 . Column 4 adds three lagged scores on the math exam. Again, all are significant. The within-school $R^{2}$ is 0.058 higher than in the specification with just a single lagged reading score. Column 5 adds 28 additional covariates, measured in grade 4 , that might help to predict students' grade-5 achievement. These include race, gender, and free lunch status indicators; measures of parental education; various categories of "exceptionality" and learning disabilities; and measures of the time spent on homework and watching TV. These are jointly highly significant, though their inclusion raises the explained share of variance by only 0.003 .

The available variables - nearly all of which were readily observable when students were assigned to $5^{\text {th }}$ grade classrooms - explain nearly $70 \%$ of the within-school variation in students' grade-5 test scores. Moreover, this substantially understates the predictability of student achievement. Recall from Section 2 that $14 \%$ of the variance in observed 5 th grade scores is noise that would not even persist into a second administration of the test a week later. This noise is irrelevant to the predictability of achievement, and is uncorrelated with all predictor variables. Table 2 also shows estimates of the explained share of the within-school variance of true achievement, net of this transitory noise. These range from 0.764 with just the 4 th grade score to 0.837 with the full set of controls.

Of course, predictions of end-of-year scores are easy: It should not be surprising that students who score highly in 4th grade tend to continue to earn high scores in 5 th grade, and all value added models control for this variation in one way or another. A harder task is to predict 5 th grade gains. So long as the $4^{\text {th }}$ grade score is included as a covariate, the coefficients in a prediction equation for gains are identical to those for levels, save that the $4^{\text {th }}$ grade score coefficient is reduced by 1 . But the explained share of variance is much lower. The bottom rows of the Table show the $R^{2}$ statistics for specifications that take grade- 5 gains as the dependent variable. These range from 0.279 to 0.398 within schools. The first-difference transformation does not eliminate predictability; the principal clearly has substantial information at his disposal for the prediction of student gain scores. ${ }^{11}$

\footnotetext{
${ }^{11}$ Neither coefficients nor fit statistics can be directly converted to those that would be seen for the true gain score, net of measurement error, because measurement error in the 4th grade score appears on both sides of the equation for 5th grade gains. I discuss in Section 6 how the coefficients of specifications for true gains can be recovered from the estimates in Table 2. True gains are quite predictable as well.
} 
Also relevant to the analysis below is the value of past gains for predicting future scores and gains. Table 3 presents specifications using grade- 4 gains as explanatory variables. These explain only $0.2 \%$ of the within-school variance in 5 th grade achievement but $18.2 \%$ of the variance in 5 th grade gains.

\section{Evidence for non-random assignment}

The simplest value added model estimates each teacher's effect as the average gain score of her students. ${ }^{12}$ In order to attribute this average gain to the teacher, it must be the case that the information used to make teaching assignments is uninformative about students' potential gains, conditional on any control variables. As shown in Section 3, prior achievement and gains are strongly predictive of future scores and gains, so correlations between teacher assignments and past gains would violate the simple VAMs identifying assumption. Rothstein $(2008 \mathrm{a}, \mathrm{b})$ tests for "effects" of $5^{\text {th }}$ grade teachers on $4^{\text {th }}$ grade gains. Given the evidence in Table 3 , effects of this sort would indicate that expected $5^{\text {th }}$ grade gains are not balanced across $5^{\text {th }}$ grade classrooms, and that the simple VAM will be biased.

Let $A_{i g}$ be the test score for student $i$ at the end of grade $g$. The grade- $g$ gain is defined as $\Delta A_{i g} \equiv A_{i g}-A_{i, g-1}$. Let $S_{i g}$ be a vector of indicators for the school attended in grade $g$ and let $T_{i g}$ be a set of teacher indicators. The simple value added model is based on the regression of gains on school and teacher indicators, with the teacher coefficients normalized to mean zero within each school:

$$
\Delta A_{i g}=S_{i g} \alpha_{g}+T_{i g} \beta_{g}+\varepsilon_{i g}
$$

In order for this regression to yield unbiased estimates, unobserved determinants of annual gains must be uncorrelated with $T_{i g}$. I evaluate this assumption by substituting in (1) the student's gain in some prior year $h<g$ :

$$
\Delta A_{i h}=S_{i g} \tilde{\alpha}_{h}+T_{i g} \tilde{\beta}_{h}+\varepsilon_{i h} .
$$

The causal effect of the grade- $g$ teacher on the gain in grade $h$ is necessarily zero. A nonzero coefficient $\tilde{\beta}_{h}$ can therefore arise only if the error in grade $h, \varepsilon_{i h}$, is correlated with the grade- $g$ teacher assignment; that is, if teacher assignments in grade $g$ depend on past outcomes. As we

\footnotetext{
${ }^{12}$ This is not a widely used model. However, it is quite similar to the implicit model of the most widely used VAM, the Tennessee Value Added Assessment System (TVAAS; see Sanders et al., 1997). This is specified as a mixed model for level scores that depend on the full history of classroom assignments, but its identifying assumption is essentially that the simple model that I consider here is an unbiased estimator of teachers' causal effects.
} 
have seen, $\varepsilon_{i h}$ is correlated with $\varepsilon_{i g}$, so any such correlation means the simple value added model will yield a biased estimate of the effect of the grade- $g$ teacher on the grade- $g$ gain. ${ }^{13}$

Table 4 presents estimates of 5th grade teachers' coefficients in models for gain scores in grades 5, 4, and 3, using specifications (1) and (2). To permit comparisons across models, I use a balanced panel of students who attended the same school for all three grades. These are similar to those reported in Table 3 of Rothstein (2008a), albeit estimated from a slightly different sample.

We begin with the model for grade-5 gains. The 3,013 elements of the $\hat{\beta}_{5}$ vector (normalized to mean zero across all 5 th grade teachers at the school) can be summarized by their standard deviation. This, 0.152 , is shown in Column $1 .{ }^{14} \mathrm{I}$ also report an adjusted standard deviation that subtracts from the across-teacher variance the contribution of sampling error to this variance (Aaronson, Barrow, and Sander 2007; Rothstein 2008a). This adjusted standard deviation, which estimates the variability of the true $\beta$ coefficients net of sampling error, is 0.107: A teacher who is one standard deviation better than average has students who gain 1/10 of a standard deviation (of achievement levels) relative to the average over the course of the year. This resembles existing estimates (Aaronson, Barrow, and Sander 2007; Kane, Rockoff, and Staiger 2008; Rivkin, Hanushek, and Kain 2005).

The remaining columns present counterfactual estimates that vary only the dependent variable. Column 2 presents estimates for 4 th grade gains. We know that there are no causal effects of 5 th grade teachers on 4 th grade gains (i.e. that $\tilde{\beta}_{4}=0$ ), so any non-zero coefficients in this specification are indicative of student sorting. The hypothesis that $\tilde{\beta}_{4}=0$ is decisively rejected, and indeed there is nearly as much variation in the elements of $\hat{\widetilde{\beta}}_{4}$ as in those of $\hat{\beta}_{5}$ : The sampling-adjusted standard deviation of 5th grade teachers' normalized "effects" on 4th grade gains is 0.080 , nearly as large as that for 5 th grade gains. Column 3 presents an analogous model where the dependent variable is the 3rd grade gain, the difference between the student's score on

\footnotetext{
${ }^{13}$ Rothstein (2008b) formalizes the test and discusses its interpretation in greater detail than is possible here. Note that the grade- $h$ teacher is a potential omitted variable in (2), and a correlation between $T_{i g}$ and $T_{i h}$ could yield a nonzero $\tilde{\beta}_{h}$ even if grade- $g$ classroom assignments do not depend on $\varepsilon_{i h}$. Rothstein (2008b) shows that the inclusion of controls for $T_{i h}$ has essentially no effect on the results.

${ }^{14}$ Across-teacher means and standard deviations are weighted by the number of students taught, and degrees of freedom are adjusted for the normalization of $\hat{\beta}_{5}$. Further details of the methods are available in Rothstein (2008a).
} 
the end-of-grade reading test and the beginning-of-the year pretest. We see even larger apparent effects of 5 th grade teachers here.

The lower portion of Table 4 presents correlations between the estimates of the coefficient vectors $\beta_{5}, \tilde{\beta}_{4}$, and $\tilde{\beta}_{3}$, first unadjusted for sampling error and then adjusted. Adjacent coefficients are highly negatively correlated, both before and after the adjustment for sampling error, but there is nearly no correlation between $\beta_{5}$ and $\tilde{\beta}_{3}$.

Two of these correlations are of particular interest here. First, $\operatorname{corr}\left(\beta_{5}, \tilde{\beta}_{4}\right)=-0.35$. This indicates that 5 th grade teachers who appear (by the simple model 1) to have high value added tend to be those whose students experienced below-average gains in grade 4. As noted earlier, gains are negatively autocorrelated at the student level; at least a portion of the variation in estimated 5th grade value added apparently reflects predictable consequences of non-random student assignments.

The second interesting correlation is that between $\tilde{\beta}_{4}$ and $\tilde{\beta}_{3},-0.36$. One hypothesis that could explain the presence of counterfactual "effects" of 5th grade teachers on earlier grades' gains is that students differ systematically in their rate of gain, and that classroom assignments depend in part on that rate. Rothstein (2008a) refers to this explanation as "static tracking"-the determinants of classroom assignments are constant across grades, and conditional on these determinants the test score in grade $g$ does not affect the teacher assignment in $g+1$. In the presence of static tracking, the bias in teacher effects coming from non-random assignment can be absorbed by pooling data on a student's gains across several grades and including student fixed effects in the specification. This sort of specification is used by Harris and Sass (2006); Koedel and Betts (2007); Jacob and Lefgren (2008); Rivkin, Hanushek, and Kain (2005); and Boyd et al. (2008), among others.

As Rothstein (2008a) notes, static tracking implies that in simple specifications like those in Table 4 the coefficients for the grade- $g$ teacher on gains in grades $h$ and $k(h, k<g)$ should be identical, up to sampling error. In other words, $\operatorname{corr}\left(\tilde{\beta}_{4}, \tilde{\beta}_{3}\right)=1 .^{15}$ This restriction does not even approximately hold in the data. Classroom assignments are evidently not made on the basis of permanent student characteristics, but respond dynamically to annual student performance. This implies that student fixed effects specifications provide inconsistent estimates of teachers' causal

\footnotetext{
${ }^{15}$ Again, this conclusion is supportable only if the correlation between $\tilde{\beta}_{4}$ and $\tilde{\beta}_{3}$ is negative in specifications that include controls for 4 th and 3rd grade teachers, where those in Table 2 do not. The correlation is nearly identical when these controls are included.
} 
effects. The only way to control for non-random classroom assignments while permitting consistent estimation of teachers' effects is to measure the determinants of assignments directly. Many value added specifications (e.g., Gordon, Kane, and Staiger 2006; Kane, Rockoff, and Staiger 2008; Aaronson, Barrow, and Sander 2007; Jacob and Lefgren 2008) control for the baseline score, in effect modeling the end-of-year score as a function of the beginning-of-year score and the teacher assignment. These specifications are robust to dynamic teacher assignments of a very restricted form: Unless teacher assignments are random conditional on the baseline score, estimates will still be biased. The estimates in Tables 2 and 3 indicate that there is a great deal of information available to principals about students' potential gains above and beyond that provided by the lagged score; there is no reason to expect that the use of this information in forming classroom assignments can be absorbed with simple controls. I show below that the once-lagged-score specification is rejected by the data.

\section{Selection on observables}

Strategies for isolating causal effects in the presence of non-random assignment of treatment (in this case, of classroom assignments) depend importantly on whether the determinants of treatment are observed or unobserved. Accordingly, I treat the two cases separately. I defer discussion of the selection-on-unobservables case to Section 6. In this Section, I assume that selection is solely on observables: 5th grade teacher assignments are random conditional on the available variables measured in 4th grade. Under this assumption, bias can be avoided by controlling for the full set of observables in the value added model. Models that use less complete controls may be biased if the included variables are unable to absorb all of the nonrandomness of teacher assignments. Note that no harm is done by controlling for variables that are not used in teacher assignments. Accordingly, I allow teacher assignments to depend on any or all of the variables included in Column 5 of Table 2 - the history of math and reading test scores plus a set of demographic and behavioral variables as measured in grade 4. I label these variables $X_{i 4}$. If 5 th grade classroom assignments are in fact random conditional on $X_{i 4}$, then the effects of 5 th grade teachers can be estimated via a simple regression of 5 th grade gains on 5 th grade school and teacher indicators with controls for the $X_{i 4}$ variables:

$$
\Delta A_{i 5}=S_{i 5} \alpha+T_{i 5} \beta+X_{i 4} \gamma+\varepsilon_{i \mathrm{js} 5} .
$$


Note that 4 th grade reading and math scores are included in $X_{i 4}$. Thus, (3) is identical to a regression that uses the 5th grade score (rather than the gain) as the dependent variable, as this simply adds $A_{i 4}$ to both sides.

Value added models (hereafter, VAMs) rarely have access to the full set of control variables included in $X_{i 4}$. Omission of any variable that influences classroom assignments may produce bias in the estimated teacher effects. To evaluate the importance of this - under the maintained assumption of selection-on-observables - I compare estimates from (3) with those obtained from three VAMs with less complete controls:

$$
\begin{array}{ll}
\text { VAM1: } & A_{i 5}=S_{i 5} a+T_{i 5} b+e_{i 5} \\
\text { VAM2: } & \Delta A_{i 5}=S_{i 5} a+T_{i 5} b+e_{i 5} \\
\text { VAM3: } & \Delta A_{i 5}=S_{i 5} a+T_{i 5} b+A_{i 4} c+e_{i 5} \\
\text { VAM4: } & \Delta A_{i 5}=S_{i 5} a+T_{i 5} b+A_{i 4} c_{4}+A_{i 3} c_{3}+A_{i 2} c_{2}+e_{i 5}
\end{array}
$$

VAM1 credits each teacher with the average achievement of students in her class (less the school-and-grade-level average). I include this "levels" specification, which few would advocate, solely as the basis for comparison to more reasonable models. VAM2 effectively controls for students' 4th grade scores, constraining their coefficients to one. Teachers are credited with students' average gain scores (again relative to the school-grade average). This is the basic specification used in most value added policy and above in Section 4. VAM3 controls for students' 4th grade achievement and estimates the coefficient on the lagged score rather than constraining it to one. In this model, teachers are credited with their students' performance relative to other students in the same school and grade with the same beginning-of-year scores. Finally, VAM4 controls not just for last year's score but for the two prior scores as well. (The $3^{\text {rd }}$ grade pre-test is denoted $A_{i 2}$ here.) This sort of specification is not widely used. It could in principle be used in some value added implementations, though unavoidable data limitations would prevent its widespread adoption. Most importantly, this VAM is not available for the assessment of teachers in the first three grades in which students are tested.

For each model, I compute the standard deviation across teachers of $b$ and of the bias relative to the coefficient vector from the richer specification (3), $b-\beta$. A useful summary statistic is the variance of the bias relative to that of teachers" "true" effects (as indicated by (3)), $\mathrm{V}(b-\beta) / \mathrm{V}(\beta)$. I also compute the correlation between the bias and the true effect, corr $(b-\beta$, $\beta$ ): It is helpful to know whether good teachers (at least as indicated by the baseline model (3)) 
are helped or hurt by the assignment process. A strong positive correlation between true effects and the bias would imply that teacher rankings are not much affected by sorting bias, while a negative correlation would indicate that biases from non-random assignments mask differences in true teacher quality.

Table 5 presents the results. Each statistic is computed first from the estimated coefficients (in the first panel), then adjusted for the influence of sampling error (second panel). The baseline specification indicates that the standard deviation of teachers' effects is 0.096 , or 0.124 before the adjustment for sampling error. VAM1 indicates much more variability of teacher effects, though this is primarily bias-the bias in this specification is more than three times as large (in variance terms) as the true variability that we are attempting to measure. The specification for gain scores, VAM2, eliminates much of the bias, but its variance is still half that of the true effects. VAM3, controlling for the 4th grade score, cuts the standard deviation of the bias in half; here, the variance of the bias is $13 \%$ of that of the quality signal. This is small in comparison with the previous models, but still substantial enough to represent a problem for policy. In each case, biases are only weakly correlated with true coefficients.

VAM4 eliminates nearly all of the bias relative to the richer selection-on-observables specification. This is unsurprising: Recall that Table 2 indicated that the control variables included in (3) but excluded from VAM4 added only $0.3 \%$ to the explained share of variance of 5 th grade achievement and $0.6 \%$ to the explained share of variance of 5 th grade gains. Thus, my assumption that specification (3) permits unbiased estimation of teachers' causal effects implies that omitted variables bias in VAM4 is negligible. To understand the true potential for bias in this specification, we will need to consider the impact of selection on information that is unobserved in my sample but is available for use in forming classroom assignments. I develop methods for assessing this in the next Section.

\section{A model of tracking on unobservables}

There is no good reason to think that classroom assignments depend only on the variables available in my data. Indeed, the presence of noise in the observed test score history strongly suggests otherwise. A principal or parent would almost certainly be able to form a less noisy measure of students' achievement each year by combining test scores with other measures (e.g. grades) that I do not observe. In this Section I develop a framework in which classroom 
assignments depend on the observed variables and on unobserved variables that have known correlations with the observables. This permits computation of the variance across teachers of the bias in feasible estimates of $\beta$, though not the bias in any individual teacher's estimated effect.

In the selection-on-observables analysis in Section 5, I allowed for the possibility that classroom assignments depended on only a subset of the observed variables. The cost of allowing for selection on unobservables is that we must rule that possibility out: I require here that the set of variables that influence classroom assignments be known precisely. I assume that assignments depend on an index formed by averaging a set of pre-specified variables with weights that best predict student outcomes. Assignments are assumed to be uncorrelated with later outcomes conditional on this index.

I assume that the researcher is able to observe some but not all of the variables from which the prediction index is formed. When all of the predictor variables are observed, the setup collapses to the selection-on-observables model discussed in Section 5. When only a subset is observed, the distribution of the observed variables across classrooms can be used to identify the importance of predicted outcomes, relative to the residual, in forming classroom assignments.

I develop the model in several parts. I begin by describing the assumed assignment process, then discuss the implications of these assignments for VAM estimation, and finally describe how the North Carolina data can be used to calibrate the model and to estimate the degree of bias in feasible VAMs that is implied by the assumed assignment process. The model is presented in terms of a principal who uses the information available to her to make classroom assignments. This is shorthand. Classroom assignments may depend on negotiation between principals, teachers, students, and parents, each of whom may observe different aspects of the student. The "principal" in my model is a black box that takes all of the information available to the various agents and outputs a classroom assignment.

\subsection{Classroom assignments}

I assume that the principal observes three classes of characteristics for each student: $Z$, characteristics that are useful predictors of student outcomes and that are observed as well by the data analyst; $W$, predictor variables that are not observed by the analyst; and $\eta$, determinants of classroom assignments that are not predictive of the academic outcomes analyzed in value added models. Let $Y$ represent the outcome. $Y$ might measure true gains or observed gains; we will see below that this has important consequences for the analysis. 
We can distinguish between the teacher's true causal effect, $T \beta$, and the other components of the outcome, $\omega=Y-T \beta$. The challenge in value added modeling is that the classroom assignment $T$ may depend on $\omega$, or at least on that part of $\omega$ that is known to the principal. Let $I \equiv \mathrm{E}[\omega \mid Z, W]$ be the principal's prediction of $\omega$, and let $\varepsilon=\omega-I$. We can measure the amount of information available to the principal by $\mathrm{V}(I) / \mathrm{V}(\omega)=\sigma_{I}^{2} /\left(\sigma_{I}^{2}+\sigma_{\varepsilon}^{2}\right)$.

I assume that classroom assignments depend on $Z$ and $W$ only through the index $I$. This is central to my strategy, as it enables me to recover the amount of sorting on the unobserved variables $W$ by measuring the degree of sorting on the observed variables $Z$. Assignments may depend in part on the non-predictive variables, $\eta$, however. It is convenient to normalize $\eta$ to be a single variable that is orthogonal to all other variables (i.e. to $Z, W$, and $\varepsilon$ ) and is scaled so that assignments depend on the simple sum $\lambda \equiv I+\eta$. Because $\eta$ is never observed by the analyst, this carries no loss of generality. I also impose the more restrictive assumption that $\{I, \eta, \varepsilon\}$ are jointly normally distributed.

Students are sorted perfectly on $\lambda$ into classes. ${ }^{16}$ That is, all of the students assigned to a particular teacher have the same $\lambda$ value. The importance of predicted outcomes in assignments is controlled by $\sigma_{\eta}{ }^{2}$ : If the principal assigns students to classrooms solely on the basis of predicted outcomes, $\sigma_{\eta}{ }^{2}=0$ and $\lambda \equiv I$. Perfect random assignment represents the opposite limiting case, $\sigma_{\eta}{ }^{2}=\infty$ and $\lambda \approx \eta$. The across-classroom variance of $I$ is the difference between the total variance and the within-classroom variance, $\mathrm{V}(I)-\mathrm{V}(I \mid \lambda)=\operatorname{corr}^{2}(I, \lambda) \mathrm{V}(I)=\sigma_{I}^{4} /\left({\sigma_{I}}^{2}+\right.$ $\sigma_{\eta}{ }^{2}$ ). This is large if predicted outcomes are the primary determinants of assignments and small if they are relatively unimportant.

\subsection{The principal's prediction}

In order to make further progress, we need to specify the information available to the principal for use in predicting outcomes (i.e. the variables $Z$ and $W$ ). I consider several scenarios in the empirical analysis below. Intermediate cases between selection-on-observables and perfect predictability of future outcomes are the most realistic and I focus on these, though I also include

\footnotetext{
${ }^{16}$ This is at best an approximation. A typical school has three to five classes per grade; even if these classes are perfectly stratified, $\lambda$ will have considerable heterogeneity within classes. With less than perfect sorting, my methods will understate the importance of $I$ (relative to $\eta$ ) in classroom assignments and therefore will understate the bias in value added models due to these assignments. The basic approach could be extended to stratification on $\lambda$ across a finite number of classes (so that one class has students with $\lambda \in\left(-\infty, c_{1}\right)$, another has $\lambda \in\left(c_{1}, c_{2}\right)$, etc.), at the cost of considerable additional complexity.
} 
the limiting cases for comparison. I begin with base cases in which selection is on observables, as in Section 5:

A. The principal has no information about future achievement gains beyond that contained in the $4^{\text {th }}$ grade test score $\left(Z=\left\{A_{4}\right\} ; W=\{\varnothing\}\right)$.

B. The principal observes the test score history, but has no additional information about achievement gains $\left(Z=\left\{A_{2}, A_{3}, A_{4}\right\} ; W=\{\varnothing\}\right)$.

Note that scenarios A \& B are falsified by the evidence in Table 2: Since the principal can observe all of the $4^{\text {th }}$ grade variables that are available in my data, the fact that these variables are useful in predicting gains indicates that the principal has more information about potential gains than just the score history. Nevertheless, these scenarios provide useful baselines.

A second set of scenarios allows the principal to be better able to disentangle the signal and noise components of the test score history than can the econometrician. The principal knows students and has access to course grades and other indicators of student achievement with which to do this. A useful parameterization is to assume that the principal has access to $k$ additional test score histories, each subject to its own error but with errors independent across tests. That is, if the true achievement history through $4^{\text {th }}$ grade is $A^{*}=\left(A_{1}{ }^{*}, \ldots, A_{4}{ }^{*}\right)$, we assume that the value added analyst observes only the measured achievement history $A=A^{*}+u$. The principal observes this as well, but also sees additional series $\left\{q_{1}, q_{2}, \ldots, q_{k}\right\}$. Each measures true achievement with independent error: $q_{j}=A^{*}+v_{j}, \mathrm{E}\left[v_{j}^{\prime} v_{j}\right]=\mathrm{E}\left[u^{\prime} u\right]$, and $\mathrm{E}\left[v_{j}^{\prime} v_{h}\right]=\mathrm{E}\left[v_{j}^{\prime} u\right]=0$. The $q$ series can be thought of as representing grades, student evaluations, or classroom observations that are available to the principal but not reported in typical data sets.

C. The principal observes the test score history that is available to the analysis, and also observes $k$ additional noisy achievement series $\left(Z=\{A\} ; W=\left\{q_{1}, \ldots, q_{k}\right\}\right)$.

In the limit as $k \rightarrow \infty$, this scenario converges to:

D. The principal observes both the test score history and the true achievement history $(Z$ $\left.=\{A\} ; W=\left\{A^{*}\right\}\right)$.

Note that the history of observed scores is not redundant in scenario D: When $Y$ is the observed gain, the lagged observed score is informative about the measurement error component in $\omega$ (i.e. about $\left.\Delta A_{g}-\Delta A_{g}{ }^{*}=u_{g}-u_{g-1}\right)$.

Even scenarios $\mathrm{C}$ and $\mathrm{D}$ are quite restrictive. As we will see, the true achievement history explains only a third of the within-school variance of true achievement gains, and it is plausible 
that the principal, who knows something of the child's family situation and emotional and cognitive development patterns, has information about the remaining portion.

E. The principal observes the test score history, the true achievement history, and an additional orthogonal signal of $\omega\left(Z=\{A\} ; W=\left\{A^{*}, G\right\}\right)$.

Results here will depend on the quantity of information that this additional signal is assumed to contain. Let the principal's prediction regression be

$\mathrm{E}\left[\omega \mid A, A^{*}, G\right]=A \varphi+A^{*} \chi+G \psi$.

Then we can index the information in $G$ by $f=V(G \psi) / V\left(A^{*} \chi\right)$. The limiting case (as $f \rightarrow$ $\left.V\left(\omega \mid A^{*}\right) / V\left(A^{*} \chi\right)^{17}\right)$ is:

F. The principal can predict the outcome perfectly $(Z=\{A\} ; \mathrm{W}=\{\omega\})$.

Note that this does not imply that students are perfectly sorted across classrooms on the basis of their potential outcomes. Recall that the principal is assumed to combine her prediction with an orthogonal term $\eta$ and sort only on that combination. A principal who could perfectly predict outcomes might still assign poorly-sorted classes if she thought ability-mixing was desirable or if her goal of tracking students by ability was balanced against other objectives. Either would correspond to a large $\sigma_{\eta}^{2}$.

Even so, $\mathrm{F}$ is not a plausible scenario for the problem at hand, as it is not realistic to suppose that principals can perfectly predict how well students will do over the course of a year. I include it because it illustrates the connection between the methods used here and those used by AET. Where in the earlier scenarios the principal observed all of the variables available to the analyst plus a subset of the remaining component of students' gains, here the principal observes both components equally. As a result, both are equally sorted across classrooms. This corresponds to AET's assumption that selection on unobservables is identical to selection on observables. $^{18}$

The six scenarios are summarized in Table 6 .

\subsection{Bias in under-controlled value added models}

\footnotetext{
${ }^{17}$ When $Y$ is the true gain and teachers have no true effects, this corresponds to $f \rightarrow\left(1-R^{2}\right) / R^{2}$, where $R^{2}$ is the explained share of variance from a regression of $\Delta A^{*}$ onto $A^{*}$. As I discuss below, $R^{2}$ is about 0.34 . Thus, this limit is just below 2 .

${ }_{18}$ Altonji et al. also consider intermediate cases, where the correlation between the unobserved determinants of selection and outcomes lies between zero (no selection) and the value corresponding to scenario F. The above framework can be seen as providing a basis for the choice of this correlation.
} 
We can write outcomes as the sum of teacher effects, the principal's prediction $I$, and the portion of outcomes that the principal was unable to predict:

$$
Y=a+T \beta+I+\varepsilon .
$$

Because $I$ is a determinant of classroom assignments, it is correlated with $T$. That is, there are differences across classrooms in student outcomes that do not reflect teacher quality. Unbiased estimation of $\beta$ requires controlling for $I$ in a value added model specified as (4). ${ }^{19}$ Unfortunately, (4) is not a feasible value added model. In most of the scenarios described above, the analyst observes only a subset of the variables used to construct $I$. The inability to control fully for $I$ produces bias in the resulting estimates.

It is easiest to characterize the bias in VAM2, which does not include any controls. $I$ is an omitted variable here, and any across-classroom component of it represents bias in $\hat{\beta}$. The variance of this bias is equal to the across-classroom variance of $I, \sigma_{I}{ }^{4} /\left(\sigma_{I}{ }^{2}+\sigma_{\eta}{ }^{2}\right)$.

In a richer VAM that includes control variables $Z$, these variables may absorb some of the bias. Write the regression of $I$ onto $T$ and $Z$ as $I=T \kappa+Z \pi+v \cdot{ }^{20}$ We can rewrite (4) as

$$
Y=a+T(\beta+\kappa)+Z \pi+(v+e) .
$$

By construction, the terms in the final parentheses are uncorrelated with both $T$ and $Z$, so do not create bias in the coefficients. But notice that the $T$ coefficient here combines the causal effect $\beta$ with an additional bias term, $\kappa$. This reflects the fact that the principal is able to predict the outcome better than can the analyst and that he uses his superior prediction in forming classroom assignments. The structure developed above makes it possible to derive the magnitude of the bias (i.e., $\mathrm{V}(T \kappa)$ ). Intuitively, sorting of students to classrooms on the basis of $I$ leads to a non-random distribution of $Z$ across classrooms, and we can use this observable distribution to identify the importance of $I$ in classroom assignments.

Formally, recall that we have assumed that $\lambda$ is perfectly sorted across classrooms and that the teacher's identity is informative about $W$ and $Z$ only through $\lambda$. This ensures that $T \kappa=\lambda \xi$ for some scalar $\xi$. We can write $I=\lambda \xi+Z \pi+v$ and, therefore, $\mathrm{V}(T \kappa)=\xi^{2} \mathrm{~V}(\lambda)=\xi^{2}\left(\sigma_{I}{ }^{2}+\sigma_{\eta}{ }^{2}\right)$. Moreover, recall that $\xi$ and $\pi$ are the coefficients from a regression of $I$ onto $\lambda$ and $Z$. Thus,

\footnotetext{
${ }^{19}$ Things are somewhat more complex if classroom assignments are based on predictions of one outcome $Y_{1}$ but another outcome $Y_{2}$ is used as the dependent variable in the value added analysis. I set this issue aside for the moment.

${ }^{20}$ Recall that $I$ is an index formed from $Z$ and $W$. Tא thus represents the component of $W$ that is correlated with $T$ conditional on $Z$, while $v$ represents the component that cannot be predicted by $\{T, Z\}$.
} 


$$
\begin{aligned}
\left(\begin{array}{l}
\xi \\
\pi
\end{array}\right) & \left.=\left(\begin{array}{c}
\lambda \\
Z
\end{array}\right)\right)^{-1}\left(\begin{array}{c}
\operatorname{cov}(\lambda, I) \\
\operatorname{cov}(Z, I)
\end{array}\right) \\
& =\left(\begin{array}{cc}
\sigma_{I}^{2}+\sigma_{\eta}^{2} & \operatorname{cov}(Z, I) \\
\operatorname{cov}(Z, I) & V(Z)
\end{array}\right)^{-1}\left(\begin{array}{c}
\sigma_{I}^{2} \\
\operatorname{cov}(Z, I)
\end{array}\right)
\end{aligned}
$$

There are thus four parameters that determine the variance of the bias in the undercontrolled model, two each deriving from the sorting process and from the choice of value added specification. The sorting parameters are ${\sigma_{I}}^{2}$, concerning the principal's ability to predict students' outcomes, and $\sigma_{\eta}{ }^{2}$, which controls the importance that the principal attaches to predicted outcomes in classroom assignments. The other parameters are $\operatorname{cov}(Z, I)$, which characterizes the relationship between the control variables included in the value added model and the principal's prediction, and $\mathrm{V}(Z)$, the readily measurable variance of the VAM control variables. With knowledge of these parameters - the calibration of which is described below we can recover the variance of the bias term.

It is useful to consider three limiting cases. First, suppose that we control for all of the predictive variables used by the principal (i.e. that we have selection on observables; $W=\{\varnothing\}$ and $\left.\sigma_{\eta}{ }^{2}>0\right)$. Then $I=Z \pi, \xi=0$, and $\mathrm{V}(\lambda \xi)=0$. This corresponds to the result that there is no bias with selection on observables, so long as all relevant observables are controlled. Second, suppose that the principal places much more weight on variables unrelated to achievement than on predicted achievement in forming assignments, $\sigma_{\eta}{ }^{2}>>\sigma_{I}{ }^{2}$. Then regardless of the content of $Z$ and $W$, there is little sorting on $I$. This means that classroom assignments are only trivially endogenous, so $\xi \approx 0$, and $V(T \kappa) \approx 0$. Finally, suppose that the principal uses only predicted achievement to form assignments, $\sigma_{\eta}{ }^{2}=0$. Then $\lambda=I$, and bias depends only on the extent to which $Z$ can account for the principal's predictions (i.e., on $\left.\mathrm{V}(\mathrm{E}[I \mid Z]) / \sigma_{I}{ }^{2}\right)$.

\subsection{Calibration}

Given a scenario characterizing the principal's information, as described above, analyses of the variance of the observed $Z$ variables and of their covariance across classrooms with $Y$ can be used to calibrate the model. There are two preliminary steps to the calibration: First, the coefficients entering into the principal's prediction are estimated. This takes advantage of the observed relationship between gains and past scores, and of the structure that the various 
scenarios place on the role of past scores in the principal's predictions. Second, the degree of sorting of students to classrooms is computed, using as an input the measured between-classroom variance in observed predictor variables. The mechanics of each step are described in detail in the appendix.

Once the parameters of the model are calibrated, the methods described in the previous subsection can be used to compute the variance of the bias in a given value added model. I consider value added models VAM2, VAM3, and VAM4 from Section 5. These are distinguished by the control variables that are included in models for the grade- $g$ gain. In each case, the control variables are subsets of the $A$ vector, so it is straightforward to compute the covariance between these variables and the principal's prediction. As indicated by equation (6), this is sufficient to compute the variance of the bias term, $V(T \kappa) .^{21}$

\section{Results}

\subsection{The principal's prediction}

Table 2 presented prediction models for the 5 th grade test score as a function of test scores in earlier grades. As discussed above, these are readily converted into predictions of 5 th grade gains given the observed achievement history. Columns 1 and 2 of Table 7 present the prediction coefficients when the predictor variables are the 4th grade reading score (column 1) or the sequence of three prior reading scores (column 2). These correspond exactly to the coefficients from columns 2 and 3 of Table 2 except that the 4 th grade score coefficient is reduced by one.

It may be that principals attempt to predict students' true gains rather than their observed gains. True gains are much harder to predict on the basis of past test scores. This is because the noisy 4th grade test score achieves predictive power for the observed 5th grade gain due to the presence of the same measurement error, $u_{4}$, in both variables. Standard errors-in-variables formulae (discussed in the Appendix) can be used to obtain the best prediction equations for true gains. These are presented in columns 3 and 4 of Table $7 .^{22}$ The within-school $R^{2}$ statistics and especially the prediction coefficients themselves are reduced in magnitude from the

\footnotetext{
${ }^{21}$ Extending the analysis to VAMs that control for non-test variables requires assumptions about the relationship between these variables and the $Z$ and $W$ variables seen by the principal. I do not pursue this here.

${ }^{22}$ In principle, the coefficients of regressions that include math scores could be recovered as well.
} 
specifications for observed gains. True achievement gains are negatively correlated with past achievement levels, but not dramatically so. ${ }^{23}$ The model for observed gains in column 2 implicitly attaches a coefficient of around $-0.81(=-0.57-(-0.24))$ to the 4 th grade gain, while the corresponding model for true gains assigns a weight of only $-0.02(=-0.07-(-0.05))$ to this gain.

Table 8 presents estimates of the coefficients that the principal would apply to the available predictor variables in scenarios $\mathrm{C}$ and $\mathrm{D}$. Columns 1-4 show prediction coefficients for observed gains, while columns 5-8 show coefficients for true gains. Columns 1 and 5 repeat the coefficients from scenario B, where only the observed test score history is available. Columns 2 and 6 show coefficients when a second, equally noisy series is available. Columns 3 and 7 show coefficients when two series are available in addition to observed scores (i.e. $k=2$ ). Note that the coefficients on the observed and unobserved series are identical in columns 6 and 7, where the dependent variable is the true gain, but that they differ in columns 2 and 3, where the observed series can be used to recover a portion of the measurement error in the observed gain. Columns 4 and 8 show predictions assuming that the principal is able to observe the history of true achievement. This substantially improves his ability to predict observed gains, as the measurement error portion of the 4th grade score can be perfectly isolated, but adds relatively little to his ability to predict true gains over what could be done with three noisy histories. In neither case is the coefficient on the $4^{\text {th }}$ grade score equal to one. This implies (among other things) that VAM2, which imposes a coefficient of 1 on the lagged achievement level, is misspecified.

\subsection{The importance of predictions in classroom assignments}

Using the coefficients from Tables 2, 7, and 8 and relying on an observed component of the principal's predictions, I can compute the variance decomposition of the principal's predictions, $I$, into within- and between-classroom components. For scenario C, I present estimates for $k=1$ and $k=2$. In scenario E, I present estimates for $f=0.25, f=0.5$, and $f=1$; the scenario of perfect information, $\mathrm{F}$, corresponds approximately to $f=1.96$.

\footnotetext{
${ }^{23}$ Note that the overall $R^{2}$ statistics are higher in columns 3 and 4 than in 1 and 2 , respectively. This is because the between-school component of observed achievement gains has very little measurement error in it. This means that a larger share of the variation of true gains than of observed gains is between schools, and also that the coefficients from within-school models for true gains are closer to the best prediction weights for across-school comparisons than are those from within-school models for observed gains.
} 
The first column of Table 9 shows the fraction of the within-school variance in gains that the principal is able to predict (i.e. $\left.\sigma_{I}{ }^{2} / \mathrm{V}(Y)\right)$ in each scenario, for true gains in the first panel and for observed gains in the second panel. The second column shows the across-school share of variance for the scenarios in which $I$ is perfectly observable. Coefficients for between-school predictions may differ from those for the within-school predictions that I focus on, so I do not compute the across-school component of the incompletely observed indices. Column 3 shows the fraction of the within-school variation that is across classrooms. This equals $\sigma_{I}^{2} /\left({\sigma_{I}}^{2}+{\sigma_{\eta}}^{2}\right)$, the weight that the principal must be placing on predicted outcomes relative to other factors in classroom assignments in order to generate the observed dispersion of past test scores across classrooms. Column 4 shows the across-classroom standard deviation in predicted gains.

Not surprisingly, the scenarios in which the principal has more information permit him to explain a larger share of the within-school variance in gains. Moreover, the richer prediction scenarios yield larger estimates of the across-classroom share of variance of predicted gains. Thus, the more information that we permit the principal to have about the student's achievement history, the larger is the bias that is implied for value added specifications (like VAM2) that do not control for across-classroom sorting.

Sorting appears to be substantially more important when the principal is presumed to be using predictions of observed rather than true gains for classroom assignments. But this can be misleading: True gains are much less variable than observed gains (with a standard deviation less than half as large). Disparities between the panels are smaller in Column 3, showing the fraction of the variance of predicted gains that is across classrooms. Even in this column, though, scenarios C-E show more sorting in the second panel. This is because observed scores form a smaller share of predicted observed gains than of predicted true gains in these scenarios (compare the $R^{2}$ statistic in Column 1 of Table 8 to those in Columns 2-4, versus that in Column 5 and those in 6-8), so the same sorting on observed variables corresponds to more overall sorting in the observed gain scenarios.

\subsection{Bias in value added models with controls for observables}

Table 9 shows that the standard deviation of across-classroom differences in predicted gain scores ranges from 0.037 to 0.191 , depending on the assumptions made about the information used in sorting. This variation is bias in specifications like VAM2 that do not control for classroom assignments. By comparison, the total across classroom standard deviation of 
observed gain scores is 0.134 . Thus, even scenarios that restrict the principal to use little more than the observed variables in classroom assignments indicate biases in simple value added models that are large relative to the effects that we hope to measure.

Table 10 presents estimates of the standard deviation of the bias in richer models that include controls for students' prior achievement. Columns 1-3 of this Table index value added models, corresponding to VAM2, VAM3, and VAM4, respectively. The bias in the simplest model (VAM2) is substantial in every scenario. Column 2 shows that the inclusion of a control for the prior year's test score eliminates much of the bias in VAM2, though there is important variation across scenarios. If we assume that the principal forms classroom assignments on the basis of his predictions of true gains (rather than observed gains) and that he has no information about students' potential gains beyond that contained in their achievement histories (as in scenarios B-D), the remaining bias in VAM3 is negligible. However, if we allow the principal to have additional information or if we assume that he sorts on the basis of predicted observed gains - as he might under an accountability regime that conditions rewards and punishments on observed gains rather than on unmeasurable true gains - then the bias remains important. If the principal observes even two independent achievement histories (e.g. the test score history plus an additional series, perhaps coming from teacher grades) and uses them in classroom assignments, the standard deviation of the bias in VAM3 is 0.043 .

Column 3 shows that much of the bias in VAM3 remains in VAM4, which controls for the full sequence of prior test scores. If the principal is assumed to observe the student's true achievement history plus another set of variables that explain an equal amount of student gains (i.e. scenario $\mathrm{E}$ with $f=1$ ), the standard deviation of the bias ranges from 0.051 to 0.076 , both large relative to the standard deviation of teachers" estimated "effects."

\section{Discussion}

Typical value added analyses treat the process by which students are assigned to teachers as ignorable, under the implicit assumption that the statistical model used can absorb any systematic non-random assignment. This would be true if, for example, classroom assignments were random conditional on students' prior-grade test scores. But there is little reason to think that this is an adequate characterization of classroom assignments. Principals have a great deal of 
information beyond the prior test score that is predictive of students' end-of-year achievement and this information is unlikely to be ignored in classroom assignments.

This paper attempts to quantify the bias that arises in value added models that fail to control for the determinants of classroom assignments. The task is straightforward if classroom assignments are assumed to be random conditional on observable variables. My analysis indicates that simple VAMs that fail to control for the dynamic process of test scores, simply modeling differences in mean gain scores across classrooms, are substantially biased by student sorting. The bias is reduced - with a variance about $15 \%$ as large as that of teachers' true effects - in a VAM that controls for the lagged score, and is further reduced when additional lagged scores are included as controls. Of course, there are costs to this: The more past scores that are required for the VAM estimation, the larger the share of students who will have to be excluded from the analysis sample for reasons of missing data. Moreover, if three years of lagged scores are needed for the VAM for 5th grade teachers, what is to be done about estimating the value added of 3rd grade teachers, who see students before they have taken three years worth of tests?

The analysis is more complex if we loosen the unrealistic assumption that all of the information considered by the principal in forming teacher assignments is available in the research dataset. I develop methods for assessing the bias when the principal is assumed to have access to a limited amount of information that the researcher cannot observe. I consider several scenarios for the information set, and estimate the bias in three value added models under each scenario.

A great deal turns out to depend on how the principal uses his information: If he weights past achievement to best predict observed gains, even a limited amount of unobserved information generates substantial biases in the sorts of value added models that are commonly used. Richer models that control the full test score history rather than just a single lagged score reduce these biases, but only if the principal has very limited information about students' potential. With less restrictive assumptions, biases remain quantitatively important even in rich value added models.

Of course, all of the analysis here (and in Rothstein (2008a, b), on which much of the analysis in Section 4 is based) uses data on 5th graders in North Carolina. It is possible that the results would differ in other data. This seems unlikely, however. Anecdotally, principals everywhere are subject to pressure from parents seeking to manage their children's classroom 
assignments. The outcome of the resulting negotiations is unlikely to depend only on variables that are observable in the data sets used for value added modeling. I therefore expect that the results here would generalize to other states and school districts where student and teacher-level accountability systems have low stakes, as in North Carolina in the period from which my data were drawn.

Of more interest is the generalizability of my results to high-stakes settings. Any attempt to predict the effect of adding stakes to the value added evaluation is necessarily speculative. But it seems reasonable to guess that strong incentives attached to student scores or teacher value added measures would strengthen the general results here. In a high stakes environment, teachers would be wise to lobby principals for students who are predicted to post large gains in the coming year, and principals would be tempted to use their control over classroom assignments to reward favored teachers. In general, one would expect more sorting on the characteristics that matter for the accountability system (i.e. lower $\sigma_{\eta}{ }^{2}$ in the model in Section 6) and therefore even larger biases in the value added scores.

Three recent studies have provided evidence that appears to validate observational valueadded estimates. On closer examination, however, all are consistent with the presence of substantial bias in these estimates. Jacob and Lefgren (2008) and Harris and Sass (2007) compare value added estimates with principals' subjective assessments of teacher quality, which might be assumed to reflect unbiased estimates of teachers' causal effects. Both papers find that the two measures are correlated, though far from perfectly. This indicates that there is at least some signal in the value added estimates. But the weak correlations leave plenty of room for non-causal factors in the VAM estimates.

Kane and Staiger (2008) compare estimates of teacher effects from a randomized experiment with observational estimates based on data prior to the experiment. They test the hypothesis that the (appropriately shrunken) observational estimate is an unbiased prediction of the causal estimate, and obtain estimates consistent with this hypothesis. There are three important sources of slippage here, however. First, Kane and Staiger test a statistical hypothesis about the joint distribution of the true coefficients and the bias; while zero bias is consistent with the null hypothesis, so are large biases that are negatively correlated with teachers' true causal 
effects. ${ }^{24}$ Second, Kane and Staiger's sample provides low power. Their standard errors are consistent with substantial attenuation of the prediction coefficient due to bias in the observational estimates. While their confidence intervals might rule out my scenario $\mathrm{F}$ (if biases are assumed to be uncorrelated with true quality), my more realistic scenarios are wholly consistent with the Kane and Staiger estimates but are nevertheless extremely troubling regarding the potential for bias in value added estimates. Finally, the Kane and Staiger analysis is based on a carefully selected sample of pairs of teachers for which principals consented to random assignment. One might expect that principal consent was more likely when the two teachers would have been given similar students in any case. If so, the results cannot be generalized beyond the sample, even to other teachers at the same schools.

The results here suggest that it is hazardous to interpret typical value added estimates as indicative of causal effects. Although some assumptions about the assignment process permit nearly unbiased estimation, other plausible assumptions yield large biases. Further evidence on the process by which students are assigned to classrooms is needed before it will be clear which types of assumptions are closest to reality. The most recent such study, Monk (1987), is now more than twenty years old. More recent evidence, from studies more directly targeted at the assumptions of value added modeling, is badly needed, as are richer VAMs that can account for real world assignments. In the meantime, causal claims will be tenuous at best.

\footnotetext{
${ }^{24}$ They test the hypothesis that $\operatorname{cov}(\beta, \kappa) / \mathrm{V}(\kappa)=1$, where $\beta$ is the vector of causal effects and $\kappa$ is the best linear predictor of $b$, the sum of causal effects and any sorting bias, based on the coefficients from the value added model. This equality will hold either if $\mathrm{V}(b-\beta)=0-$ i.e., there is no bias - or if $\operatorname{corr}(\beta, b-\beta)=-\sqrt{V(b-\beta) / V(\beta)}$.
} 


\section{References}

Aaronson, Daniel, Lisa Barrow, and William Sander. 2007. Teachers and Student Achievement in the Chicago Public High Schools. Journal of Labor Economics 24 (1): 95-135.

Altonji, Joseph G., Todd E. Elder, and Christopher R. Taber. 2005. Selection on observed and unobserved variables: Assessing the effectiveness of Catholic schools. Journal of Political Economy 113 (1): 151-184.

Ballou, Dale. 2002. Sizing up test scores. Education Next 2 (2): 10-15.

Bazemore, Mildred. 2004. North Carolina reading comprehension tests. Technical report (citable draft), Office of Curriculum and School Reform Services, North Carolina Department of Public Instruction.

Boyd, Donald, Hamilton Lankford, Susanna Loeb, Jonah Rockoff, and James Wyckoff. 2008. The narrowing gap in New York City teacher qualifications and its implications for student achievement in high-poverty schools. Journal of Policy Analysis and Management 27 (4): 793-818.

Clotfelter, Charles T., Helen F. Ladd, and Jacob L. Vigdor. 2006. Teacher-student matching and the assessment of teacher effectiveness. Journal of Human Resources 41 (4): 778-820.

Goldhaber, Dan. 2007. Everyone's doing it, but what does teacher testing tell us about teacher effectiveness? Journal of Human Resources 42 (4): 765-794.

Gordon, Robert, Thomas J. Kane, and Douglas O. Staiger. 2006. Identifying effective teachers using performance on the job. Hamilton Project Discussion Paper No. 2006-01.

Harris, Douglas N., and Tim R. Sass. 2006. Value-added models and the measurement of teacher quality. Unpublished paper, Florida State University.

Harris, Douglas N., and Tim R. Sass. 2007. What makes for a good teacher and who can tell? Unpublished paper, Florida State University.

Jacob, Brian A., and Lars Lefgren. 2008. Can principals identify effective teachers? Evidence on subjective performance evaluation in education. Journal of Labor Economics 25 (1): 101-136.

Kane, Thomas J., and Douglas O. Staiger. 2008. Estimating teacher impacts on student achievement: An experimental evaluation. NBER Working Paper No. 14607

Kane, Thomas J., Jonah E. Rockoff, and Douglas O. Staiger. 2008. What does certification tell us about teacher effectiveness? Evidence from New York City. Economics of Education Review 27 (6): 615-631. 
Koedel, Cory, and Julian R. Betts. 2007. Re-examining the role of teacher quality in the educational production function. Working paper 07-08, University of Missouri Department of Economics April.

Martineau, Joseph A. 2006. Distorting value added: The use of longitudinal, vertically scaled student achievement data for growth-based, value-added accountability. Journal of Educational and Behavioral Statistics 31 (1): 35-62.

Monk, David H. 1987. Assigning elementary pupils to their teachers. Elementary School Journal 88 (2): 167-187.

Rivkin, Steven G., Eric A. Hanushek, and John F. Kain. 2005. Teachers, schools, and academic achievement. Econometrica 73 (2): 417-458.

Rothstein, Jesse. 2008a. Teacher quality in educational production: Tracking, decay, and student achievement. Princeton University Education Research Section Working Paper No. 25.

Rothstein, Jesse. 2008b. Teacher quality in educational production: Tracking, decay, and student achievement. NBER Working Paper No. 14442.

Sanders, William L., and Sandra P. Horn. 1994. The Tennessee value-added assessment system (TVAAS): Mixed-model methodology in educational assessment. Journal of Personnel Evaluation in Education 8 (3): 299-311.

Sanders, William L., Arnold M. Saxton, and Sandra P. Horn. 1997. The Tennessee value-added assessment system: A quantitative, outcomes-based approach to educational assessment. In Grading teachers, grading schools: Is student achievement a valid evaluation measure?, edited by Jason Millman, pp 137-162. Thousand Oaks, CA: Corwin.

Sanford, Eleanor E. 1996. North Carolina end-of-grade tests: reading comprehension, mathematics. Technical report No. 1, Division of Accountability/Testing, Office of Instructional and Accountability Services, North Carolina Department of Public Instruction.

Yen, Wendy. 1986. The choice of scale for educational measurement: An IRT perspective. Journal of Educational Measurement 23 (4): 299-325. 


\section{Appendix: Calibration methods}

This appendix describes the methods used to calibrate the model developed in Section 6. There are two steps to this calibration. First, given an assumption about the information available to the principal for use in predicting student outcomes, we need to obtain the coefficients on the variables (some observed and some not) in the prediction equation. Second, we use these coefficients and the across-classroom share of variance of the observed predictor variables to identify the parameters of the sorting process, in particular the importance of predicted outcomes to classroom assignments.

\section{A.1. Estimating the prediction coefficients}

Table 2 presents estimates of the $\varphi$ coefficients for scenarios $\mathrm{A}$ and $\mathrm{B}$, when $Y$ is the observed gain score. Estimates for predictions of true gain scores, measured without error, can be computed using omitted variables formulae. The computation for scenario A illustrates the method. Here, we hope to recover the coefficient from a regression of the true grade- $g$ gain on the observed lagged score,

$$
\Delta A_{g}{ }^{*}=A_{g-1} \varphi_{A}{ }^{*}+v^{*} .
$$

We can readily estimate the coefficient from a corresponding regression for the observed gain,

$$
\Delta A_{g}=A_{g-1} \varphi_{A}+v .
$$

My approach is to rewrite the observed gain as the true gain $\Delta A_{g}{ }^{*}$ plus the difference between the measurement errors in the $g$ and $g$-1 scores: $\Delta A_{g}=\Delta A_{g}{ }^{*}+u_{g}-u_{g-1}$. Thus, $\varphi_{A}$ equals $\varphi_{A}{ }^{*}$ plus the coefficient from a regression of $u_{g}-u_{g-1}$ on $A_{g-1}, \operatorname{cov}\left(u_{g}-u_{g-1}, A_{g-1}\right) / \mathrm{V}\left(A_{g-1}\right)$. Because the test measurement error is independent across grades, $\operatorname{cov}\left(u_{g}, A_{g-1}\right)=0$. $\operatorname{But} \operatorname{cov}\left(u_{g-1}, A_{g-1}\right) \neq 0$. The key to obtaining this covariance is to note that $u_{g-1}$ is orthogonal to $A_{g-1}{ }^{*}$ by definition. Thus, $\mathrm{E}\left[A_{g-1} u_{g-1}\right]=\mathrm{E}\left[u_{g-1}{ }^{2}+A_{g-1}{ }^{*} u_{g-1}\right]=\mathrm{V}\left(u_{g-1}\right)$. As a result, we can write $\varphi_{A}=\varphi_{A}{ }^{*}-\mathrm{V}\left(u_{g-1}\right) / \mathrm{V}\left(A_{g-1}\right)$. The fraction here is simply one minus the reliability ratio of $A_{g-1}$. A simple extension of this to the multivariate case yields coefficients for scenario B.

Similar methods can be used to recover the coefficients in scenarios C and D, for either definition of $Y$. Begin with scenario $\mathrm{D}$ when $Y$ is the true gain. We have already discussed a method for obtaining $\varphi_{B} \equiv\left(\mathrm{E}\left[A A^{\prime}\right]\right)^{-1} \mathrm{E}\left[A\left(\Delta A_{g}{ }^{*}\right)^{\prime}\right]$, the coefficients of a regression of true gains on the observed score history. A standard errors-in-variables formula relates these to the coefficients for predictions of true gains from the true achievement history, $\varphi_{D} \equiv\left(\mathrm{E}\left[A^{*} A^{*}\right]\right)^{-1} \mathrm{E}\left[A^{*}\left(\Delta A_{g}^{*}\right)^{\prime}\right]$ : 


$$
\varphi_{B}=\left(I-\left(\mathrm{E}\left[A A^{\prime}\right]\right)^{-1} \mathrm{E}\left[u u^{\prime}\right]\right) \chi_{\mathrm{D}}
$$

Inversion of this formula provides an expression for $\chi_{\mathrm{D}}$. It is straightforward to extend this to the case where $Y$ is instead the observed gain.

Now consider scenario $\mathrm{C}$, where the principal observes $k+1$ noisy measures of the achievement history but not the history itself. If $Y$ is the true gain, the principal's best prediction will use the average of his measures, $\bar{A}=\frac{1}{k+1}\left(A+q^{1}+\ldots+q^{k}\right)$. The variance of the measurement error in this average will equal $1 /(k+1)$ times the variance of the error in a single series. Thus, when $k+1$ series are available the coefficients for each series will be

$$
\varphi_{C}=\frac{1}{k+1}\left(I-\frac{1}{k+1}\left(\mathrm{E}\left[A A^{\prime}\right]\right)^{-1} \mathrm{E}\left[u u^{\prime}\right]\right) \varphi_{\mathrm{D}} .
$$

(Note that this is identical to (A3) when $k=0$.) When $Y$ is instead the observed gain, the coefficients on the observed history will deviate from those for the $k$ other histories. The correction for the presence of correlated measurement error in the dependent variable and one of the independent variables is again straightforward.

Scenarios $\mathrm{E}$ and $\mathrm{F}$ differ, in that not all of the coefficients can be estimated directly. The prediction coefficients for observed and true past achievement are in scenario $D$. The coefficient on the additional prediction variable $G$ can be normalized to one, as variation in this coefficient is equivalent to variation in $f$, the ratio of the principal's information about the component of gains that is orthogonal to the achievement history to the information contained in that history.

\section{A.2. Recovering the sorting parameters}

With estimates of coefficients for predictor variables with known variance, it is trivial to compute $\sigma_{I}^{2}$. The next step is to estimate the extent to which students are sorted across classrooms on the basis of $I$. I assemble the $Z$ variables (past test scores) into a single index $Z \pi$, using coefficients that correspond to the principal's prediction in the relevant scenario. The choice of scenario pins down $\operatorname{cov}(I, Z \pi)$. We can recover $\sigma_{\eta}{ }^{2}$ by analyzing the between-classroom variance of $Z \pi$. The within-classroom variance is 


$$
\begin{aligned}
\mathrm{V}(Z \pi \mid \lambda) & =\mathrm{V}(Z \pi)\left(1-\operatorname{corr}^{2}(Z \pi, \lambda)\right) \\
& =\mathrm{V}(Z \pi)-\frac{\operatorname{cov}^{2}(Z \pi, \lambda)}{\mathrm{V}(\lambda)} \\
& =\mathrm{V}(Z \pi)-\frac{\operatorname{cov}^{2}(Z \pi, I)}{\sigma_{I}^{2}+\sigma_{\eta}^{2}}
\end{aligned}
$$

Rearranging terms, we obtain

$$
\sigma_{\eta}^{2}=\frac{\operatorname{cov}^{2}(Z \pi, I)}{\mathrm{V}(Z \pi)-\mathrm{V}(Z \pi \mid \lambda)}-\sigma_{I}^{2}
$$

Note that the denominator here is simply the across-class variance of $Z \pi$. 
Table 1A: Summary statistics and correlations for reading test scores and gains

\begin{tabular}{|c|c|c|c|c|c|}
\hline & \multicolumn{4}{|c|}{ Score levels } & \multirow{2}{*}{$\begin{array}{l}5 \text { th grade } \\
\text { gain }\end{array}$} \\
\hline & $\begin{array}{l}\text { Pretest (start of } \\
\text { 3rd grade) }\end{array}$ & $\begin{array}{l}\text { 3rd } \\
\text { grade }\end{array}$ & $\begin{array}{l}\text { 4th } \\
\text { grade }\end{array}$ & $\begin{array}{l}5 \text { th } \\
\text { grade }\end{array}$ & \\
\hline & (1) & (2) & (3) & (4) & (5) \\
\hline Mean & -0.82 & 0.07 & 0.42 & 1.05 & 0.63 \\
\hline Standard deviation & 0.87 & 0.96 & 0.95 & 0.82 & 0.55 \\
\hline Correlations & & & & & \\
\hline 3rd grade pretest & 1 & 0.70 & 0.69 & 0.65 & -0.23 \\
\hline 3rd grade end-of-grade & 0.70 & 1 & 0.80 & 0.77 & -0.25 \\
\hline 4th grade end-of-grade & 0.69 & 0.80 & 1 & 0.81 & -0.52 \\
\hline 5th grade end-of-grade & 0.65 & 0.77 & 0.81 & 1 & 0.07 \\
\hline 5th grade gain & -0.23 & -0.25 & -0.52 & 0.07 & 1 \\
\hline
\end{tabular}

Notes: Sample includes only students for whom all four scores were available. See text for details. $\mathrm{N}=49,453$. 
Table 1B: Summary statistics and correlations for reading achievement levels and growth, net of measurement error

\begin{tabular}{lcccccc}
\hline \hline & \multicolumn{4}{c}{ Achievement levels } & \multirow{2}{*}{$\begin{array}{c}\text { 5th grade } \\
\text { growth }\end{array}$} \\
\cline { 2 - 5 } & $\begin{array}{c}\text { Pretest (start of } \\
\text { 3rd grade) }\end{array}$ & 3rd grade & 4th grade & 5th grade & & \\
\cline { 2 - 5 } & $\mathbf{( 1 )}$ & $\mathbf{( 2 )}$ & $\mathbf{( 3 )}$ & $\mathbf{( 4 )}$ & $\mathbf{( 5 )}$ \\
\hline Mean & -0.82 & 0.07 & 0.42 & 1.05 & 0.63 \\
Standard deviation & 0.74 & 0.88 & 0.88 & 0.75 & 0.27 \\
Correlations & & & & & \\
$\quad$ Pretest & 1 & 0.91 & 0.89 & 0.84 & -0.56 \\
$\quad$ 3rd grade end-of-grade & 0.91 & 1 & 0.96 & 0.92 & -0.57 \\
$\quad$ 4th grade end-of-grade & 0.89 & 0.96 & 1 & 0.96 & -0.59 \\
$\quad$ 5th grade end-of-grade & 0.84 & 0.92 & 0.96 & 1 & -0.33 \\
$\quad$ 5th grade gain & -0.56 & -0.57 & -0.59 & -0.33 & 1 \\
\hline \hline
\end{tabular}

Notes: Sample includes only students for whom all four scores were available. See text for details. $\mathrm{N}=49,453$. 
Table 2: Predictability of 5th grade reading scores from prior information

\begin{tabular}{|c|c|c|c|c|c|}
\hline & $\overline{(1)}$ & $\overline{(2)}$ & $\overline{(3)}$ & $\overline{(4)}$ & $\overline{\overline{(5)}}$ \\
\hline 4th grade reading score & & $\begin{array}{c}0.680 \\
(0.003)\end{array}$ & $\begin{array}{c}0.430 \\
(0.004)\end{array}$ & $\begin{array}{c}0.356 \\
(0.005)\end{array}$ & $\begin{array}{c}0.347 \\
(0.005)\end{array}$ \\
\hline 3rd grade reading score & & & $\begin{array}{l}0.245 \\
(0.004)\end{array}$ & $\begin{array}{c}0.196 \\
(0.004)\end{array}$ & $\begin{array}{c}0.186 \\
(0.004)\end{array}$ \\
\hline Pretest (start of 3rd grade) reading score & & & $\begin{array}{c}0.082 \\
(0.003)\end{array}$ & $\begin{array}{c}0.066 \\
(0.003)\end{array}$ & $\begin{array}{c}0.063 \\
(0.003)\end{array}$ \\
\hline 4th grade math score & & & & $\begin{array}{c}0.120 \\
(0.005)\end{array}$ & $\begin{array}{c}0.109 \\
(0.005)\end{array}$ \\
\hline 3rd grade math score & & & & $\begin{array}{c}0.045 \\
(0.005)\end{array}$ & $\begin{array}{c}0.041 \\
(0.005)\end{array}$ \\
\hline Pretest (start of 3rd grade) math score & & & & $\begin{array}{c}0.020 \\
(0.005)\end{array}$ & $\begin{array}{c}0.017 \\
(0.005)\end{array}$ \\
\hline $\begin{array}{l}\text { Non-test covariates } \\
\mathrm{N}\end{array}$ & $\begin{array}{c}n \\
49,453\end{array}$ & $\begin{array}{c}n \\
49,453\end{array}$ & $\begin{array}{c}n \\
49,453\end{array}$ & $\begin{array}{c}n \\
49,409\end{array}$ & $\begin{array}{c}y \\
49,285\end{array}$ \\
\hline $\begin{array}{l}\text { Goodness-of-fit measures } \\
\quad \text { Models for G5 achievement }\end{array}$ & & & & & \\
\hline $\mathrm{R} 2$ & 0.131 & 0.683 & 0.722 & 0.733 & 0.736 \\
\hline R2, within school & $\mathrm{n} / \mathrm{a}$ & 0.635 & 0.680 & 0.693 & 0.696 \\
\hline $\begin{array}{l}\text { R2, within school, for true achievement } \\
\text { Models for G5 gains }\end{array}$ & $\mathrm{n} / \mathrm{a}$ & 0.764 & 0.819 & 0.834 & 0.837 \\
\hline $\begin{array}{l}\text { R2 } \\
\text { R2, within school }\end{array}$ & $\begin{array}{l}0.047 \\
\mathrm{n} / \mathrm{a}\end{array}$ & $\begin{array}{l}0.313 \\
0.279\end{array}$ & $\begin{array}{l}0.397 \\
0.367\end{array}$ & $\begin{array}{l}0.421 \\
0.392\end{array}$ & $\begin{array}{l}0.427 \\
0.398\end{array}$ \\
\hline
\end{tabular}

Notes: All columns include fixed effects for 838 schools. Standard errors, clustered at the school level, in parentheses. "Non-test covariates" in column (5) include indicators for gender, for race/ethnicity, for learning disabilities in reading or in any area, for Title 1 participation, for each possible "exceptionality" (gifted, hearing impaired, mentally handicapped, etc.), for parental years of education, for free and for reduced-price lunch participation, for reporting never doing any homework; and a linear control for the number of hours of TV watched each school day (plus a dummy for missing values for this variable). 
Table 3: Prediction models with past gains as predictors

\begin{tabular}{|c|c|c|c|c|c|c|}
\hline & \multicolumn{6}{|c|}{ Dependent variable } \\
\hline & \multicolumn{3}{|c|}{ Grade 5 reading score } & \multicolumn{3}{|c|}{ Grade 5 reading gain } \\
\hline & (1) & (2) & (3) & (4) & (5) & (6) \\
\hline 4 th grade reading gain & $\begin{array}{c}0.051 \\
(0.007)\end{array}$ & $\begin{array}{c}0.082 \\
(0.007)\end{array}$ & $\begin{array}{c}0.430 \\
(0.004)\end{array}$ & $\begin{array}{l}-0.394 \\
(0.005)\end{array}$ & $\begin{array}{l}-0.410 \\
(0.005)\end{array}$ & $\begin{array}{l}-0.570 \\
(0.004)\end{array}$ \\
\hline 4 th grade math gain & & $\begin{array}{l}-0.130 \\
(0.008)\end{array}$ & & & $\begin{array}{c}0.067 \\
(0.005)\end{array}$ & \\
\hline 3rd grade reading gain & & & $\begin{array}{c}0.675 \\
(0.004)\end{array}$ & & & $\begin{array}{l}-0.325 \\
(0.004)\end{array}$ \\
\hline Pretest score, reading & & & $\begin{array}{c}0.757 \\
(0.003)\end{array}$ & & & $\begin{array}{l}-0.243 \\
(0.003)\end{array}$ \\
\hline $\mathrm{N}$ & 49,453 & 49,435 & 49,453 & 49,453 & 49,435 & 49,453 \\
\hline Goodness-of-fit measur & & & & & & \\
\hline R2 & 0.132 & 0.140 & 0.722 & 0.221 & 0.225 & 0.397 \\
\hline R2, within school & 0.002 & 0.010 & 0.680 & 0.182 & 0.186 & 0.367 \\
\hline
\end{tabular}

Notes: All columns include fixed effects for 838 schools. Standard errors, clustered at the school level, in parentheses. 
Table 4. Simple models for 5th grade teachers' "effects" on gains in 3 rd, 4th, and 5th grades

\begin{tabular}{|c|c|c|c|}
\hline & \multicolumn{3}{|c|}{ Gain score measured in: } \\
\hline & 5 th grade & 4th grade & 3rd grade \\
\hline & (1) & (2) & (3) \\
\hline \multicolumn{4}{|c|}{ Standard deviation of normalized teacher coefficients } \\
\hline Unadjusted for sampling error & 0.152 & 0.142 & 0.170 \\
\hline Adjusted for sampling error & 0.107 & 0.080 & 0.097 \\
\hline \multicolumn{4}{|c|}{ Correlations, unadjusted for sampling error } \\
\hline 5th grade & 1 & -0.39 & -0.06 \\
\hline 4th grade & -0.39 & 1 & -0.40 \\
\hline 3rd grade & -0.06 & -0.40 & 1 \\
\hline \multicolumn{4}{|c|}{ Correlations, adjusted for sampling error } \\
\hline 5th grade & 1 & -0.35 & -0.08 \\
\hline 4th grade & -0.35 & 1 & -0.36 \\
\hline 3rd grade & -0.08 & -0.36 & 1 \\
\hline
\end{tabular}

Notes: All specifications include fixed effects for 5 th grade schools and for 5 th grade teachers, normalized to mean zero at each school; only the dependent variable changes. Sample excludes 111 teachers with fewer than 10 sample students each. The remaining sample has 49,235 students, 2,733 teachers, 784 schools. Correlations are between teacher coefficients in the three specifications, weighted by the number of students taught and adjusted for the degrees of freedom absorbed by the school-level normalization. 
Table 5. Bias in simple value added specifications if classroom assignment is random conditional on observables

\begin{tabular}{ccccc}
\hline \hline & $\begin{array}{c}\text { SD of teacher } \\
\text { coefficients }\end{array}$ & $\begin{array}{c}\text { SD of } \\
\text { bias }\end{array}$ & $\begin{array}{c}\text { Bias variance I } \\
\text { total (correct) } \\
\text { variance }\end{array}$ & $\begin{array}{c}\text { corr(bias, } \\
\text { true effect) }\end{array}$ \\
\cline { 2 - 5 } & $\mathbf{( 1 )}$ & $\mathbf{( 2 )}$ & $\mathbf{( 3 )}$ & $\mathbf{( 4 )}$ \\
\hline Panel 1: Unadjusted for sampling error & & & & \\
Control for all observables & 0.124 & 0 & & 0.09 \\
Levels, no controls (VAM1) & 0.251 & 0.208 & $279 \%$ & -0.05 \\
Gain scores, no controls (VAM2) & 0.153 & 0.095 & $59 \%$ & 0.06 \\
Control for lagged score (VAM3) & 0.137 & 0.050 & $16 \%$ & 0.06 \\
Control for score history (VAM4) & 0.128 & 0.025 & $4 \%$ & \\
& & & & \\
Panel 2: Adjusted for sampling error & & & & 0.14 \\
Control for all observables & 0.096 & 0.000 & $318 \%$ & -0.09 \\
Levels, no controls (VAM1) & 0.208 & 0.171 & $53 \%$ & 0.11 \\
Gain scores, no controls (VAM2) & 0.114 & 0.070 & $13 \%$ & 0.11 \\
Control for lagged score (VAM3) & 0.106 & 0.035 & $3 \%$ & \\
Control for score history (VAM4) & 0.100 & 0.018 & & \\
\hline \hline
\end{tabular}

Notes: Specification that controls for "all observables" includes controls for math and reading scores in grades 2, 3, and 4; indicators for gender, for race/ethnicity, for learning disabilities in reading or in any area, for Title 1 participation, for each possible "exceptionality" (gifted, hearing impaired, mentally handicapped, etc.), for parental years of education, for free and for reducedprice lunch participation, and for reporting never doing any homework; and a linear control for the number of hours of TV watched each school day (plus a dummy for missing values for this variable). 
Table 6. Scenarios for the principal's information about student gains

\begin{tabular}{|c|c|c|}
\hline \multirow{3}{*}{\multicolumn{2}{|c|}{$\begin{array}{l}\text { Scenario Principal's inf } \\
\text { Selection on observables }\end{array}$}} & \multirow[t]{3}{*}{ rmation set for use in 5th grade classroom assignments } \\
\hline & & \\
\hline & & \\
\hline B & $A=\left\{A_{2}, A_{3}, A_{4}\right\}$ & $\begin{array}{l}\text { Principal observes full history of test scores: } 3 \text { rd and } 4 \text { th grade end-of- } \\
\text { grade plus } 2 \text { nd grade pre-test. }\end{array}$ \\
\hline \multicolumn{3}{|c|}{ Selection on observed and some unobserved variables } \\
\hline C & $\left\{A, q^{1}, \ldots, q^{k}\right\}$ & $\begin{array}{l}\text { Principal observes history of test scores plus } \mathrm{k} \text { addl. sequences, each } \\
\text { a noisy measure of true achievement in grades } 2-4 \text {. }\end{array}$ \\
\hline D & $\left\{A^{*}, A_{4}\right\}$ & $\begin{array}{l}\text { Principal observes true achievement history (without measurement } \\
\text { error) plus observed } 4 \text { th grade test score }\end{array}$ \\
\hline $\mathbf{E}$ & $\left\{A^{*}, A_{4}, W\right\}$ & $\begin{array}{l}\text { Principal observes true achievement history, observed } 4 \text { th grade } \\
\text { score, and an additional measure that is predictive of } A^{*}-E\left[\Delta A^{*} \mid A^{*}\right]\end{array}$ \\
\hline \multicolumn{3}{|c|}{ Selection on unobservables is like selection on observables } \\
\hline $\mathbf{F}$ & $\{Y\}$ & Principal is able to perfectly predict student outcomes \\
\hline
\end{tabular}


Table 7: Models for observed and true (measured without error) 5th grade reading gains

\begin{tabular}{|c|c|c|c|c|}
\hline \multirow{4}{*}{ Scenario: } & \multicolumn{4}{|c|}{ Dependent variable } \\
\hline & \multicolumn{2}{|c|}{ Observed gains } & \multicolumn{2}{|c|}{ True achievement gains } \\
\hline & $\mathbf{A}$ & B & A & $\mathbf{B}$ \\
\hline & (1) & $(2)$ & (3) & (4) \\
\hline 4th grade reading score & $\begin{array}{l}-0.320 \\
(0.003)\end{array}$ & $\begin{array}{l}-0.570 \\
(0.004)\end{array}$ & $\begin{array}{l}-0.150 \\
(0.003)\end{array}$ & $\begin{array}{c}-0.073 \\
(0.004)\end{array}$ \\
\hline 3rd grade reading score & & $\begin{array}{c}0.245 \\
(0.004)\end{array}$ & & $\begin{array}{l}-0.055 \\
(0.004)\end{array}$ \\
\hline Pretest (start of 3rd grade) reading score & & $\begin{array}{c}0.082 \\
(0.003)\end{array}$ & & $\begin{array}{c}-0.051 \\
(0.003)\end{array}$ \\
\hline R2 & 0.313 & 0.397 & 0.449 & 0.484 \\
\hline R2, within school & 0.279 & 0.367 & 0.273 & 0.312 \\
\hline
\end{tabular}

Notes: See text for computational details. Standard errors (in parentheses) allow for school-level clustering but treat the test reliability as known perfectly. In practice, this is estimated, likely with substantial sampling and non-sampling error. 
Table 8. Prediction weights if principal has more information than just the observed test score history

\begin{tabular}{|c|c|c|c|c|c|c|c|c|}
\hline \multirow{3}{*}{ Scenario: } & \multicolumn{4}{|c|}{ Predictions of observed gains } & \multicolumn{4}{|c|}{ Predictions of true gains } \\
\hline & $\mathbf{B}$ & C & C & D & B & C & C & D \\
\hline & (1) & (2) & (3) & (4) & (5) & (6) & (7) & (8) \\
\hline \multicolumn{9}{|c|}{ Observed test score history } \\
\hline 4 th grade & -0.57 & -0.74 & -0.81 & -1.00 & -0.07 & -0.04 & -0.03 & 0.00 \\
\hline 3rd grade & 0.24 & 0.11 & 0.07 & 0.00 & -0.06 & -0.03 & -0.02 & 0.00 \\
\hline 2nd grade & 0.08 & 0.02 & 0.00 & 0.00 & -0.05 & -0.03 & -0.02 & 0.00 \\
\hline \multicolumn{9}{|c|}{ Second noisy achievement history } \\
\hline 4 th grade & & 0.26 & 0.19 & & & -0.04 & -0.03 & \\
\hline 3rd grade & & 0.11 & 0.07 & & & -0.03 & -0.02 & \\
\hline 2nd grade & & 0.02 & 0.00 & & & -0.03 & -0.02 & \\
\hline \multicolumn{9}{|c|}{ Third noisy achievement history } \\
\hline 4 th grade & & & 0.19 & & & & -0.03 & \\
\hline 3rd grade & & & 0.07 & & & & -0.02 & \\
\hline 2 nd grade & & & 0.00 & & & & -0.02 & \\
\hline \multicolumn{9}{|c|}{ History of true achievement } \\
\hline 4th grade & & & & 0.90 & & & & -0.10 \\
\hline 3rd grade & & & & 0.00 & & & & 0.00 \\
\hline 2nd grade & & & & -0.10 & & & & -0.10 \\
\hline R2 (within school) & 0.37 & 0.44 & 0.46 & 0.54 & 0.31 & 0.33 & 0.33 & 0.35 \\
\hline
\end{tabular}

Notes: All coefficients are for within-school predictions. See text for details of computations. 
Table 9: Variance decompositions for actual and predicted 5th grade gains

\begin{tabular}{|c|c|c|c|c|}
\hline \multirow[b]{2}{*}{$\begin{array}{l}\text { Predicted variable } \\
\text { Scenario } \\
\text { Predictor variables }\end{array}$} & \multirow[b]{2}{*}{$\begin{array}{c}\text { Explained } \\
\text { share of } \\
\text { within- } \\
\text { school } \\
\text { variance } \\
(1)\end{array}$} & \multicolumn{3}{|c|}{ ANOVA for predicted gains } \\
\hline & & $\begin{array}{l}\text { Across- } \\
\text { school } \\
\text { share } \\
(2)\end{array}$ & $\begin{array}{l}\text { Fr. of within- } \\
\text { school variance } \\
\text { that is across } \\
\text { classrooms } \\
\text { (3) }\end{array}$ & $\begin{array}{l}\text { SD of across- } \\
\text { class, within- } \\
\text { school } \\
\text { component } \\
(4)\end{array}$ \\
\hline \multicolumn{5}{|l|}{ True gain } \\
\hline A Using 4th grade score & $27.3 \%$ & $12.3 \%$ & $7.3 \%$ & 0.037 \\
\hline B Using 3 prior scores & $31.2 \%$ & $12.3 \%$ & $7.5 \%$ & 0.040 \\
\hline C Using 2 independent achievement histories & $32.7 \%$ & -- & $7.8 \%$ & 0.041 \\
\hline C Using 3 independent achievement histories & $33.2 \%$ & -- & $7.9 \%$ & 0.041 \\
\hline D Using true achievement history & $34.5 \%$ & -- & $8.4 \%$ & 0.043 \\
\hline E Using true history \& $\mathrm{G}$ variable $(\mathrm{f}=0.25)$ & $43.2 \%$ & -- & $10.5 \%$ & 0.054 \\
\hline E Using true history \& $\mathrm{G}$ variable $(\mathrm{f}=0.5)$ & $51.8 \%$ & -- & $12.5 \%$ & 0.065 \\
\hline E Using true history \& $\mathrm{G}$ variable $(\mathrm{f}=1)$ & $69.1 \%$ & -- & $16.7 \%$ & 0.087 \\
\hline F Using perfect information $(\mathrm{f}=1.96)$ & $102 \%$ & -- & $24.8 \%$ & 0.129 \\
\hline \multicolumn{5}{|l|}{ Observed gain } \\
\hline A Using 4th grade score & $27.9 \%$ & $12.3 \%$ & $7.3 \%$ & 0.079 \\
\hline B Using 3 prior scores & $36.7 \%$ & $9.3 \%$ & $5.9 \%$ & 0.082 \\
\hline C Using 2 independent achievement histories & $43.5 \%$ & -- & $9.8 \%$ & 0.111 \\
\hline C Using 3 independent achievement histories & $46.2 \%$ & -- & $11.2 \%$ & 0.123 \\
\hline D Using obs. \& true achievement histories & $54.0 \%$ & -- & $14.1 \%$ & 0.149 \\
\hline E Using true history \& $G$ variable $(f=0.25)$ & $55.9 \%$ & -- & $14.6 \%$ & 0.155 \\
\hline E Using true history \& $\mathrm{G}$ variable $(\mathrm{f}=0.5)^{\prime}$ & $57.9 \%$ & -- & $15.1 \%$ & 0.160 \\
\hline E Using true history \& $\mathrm{G}$ variable $(\mathrm{f}=1)$ & $61.7 \%$ & -- & $16.1 \%$ & 0.171 \\
\hline F Using true gains $(f=1.96)$ plus obs scores & $69.1 \%$ & -- & $18.1 \%$ & 0.191 \\
\hline 5 th grade gain (observed) & 1 & $4.7 \%$ & $5.8 \%$ & 0.134 \\
\hline
\end{tabular}


Table 10. Bias in value added measures if information is used in teacher assignments that is not observed by the researcher

\begin{tabular}{|c|c|c|c|}
\hline & \multicolumn{3}{|c|}{ Value added model controls for: } \\
\hline & $\begin{array}{l}\text { Nothing } \\
\text { (VAM2) }\end{array}$ & $\begin{array}{c}\text { Lagged score } \\
\text { (VAM3) }\end{array}$ & $\begin{array}{c}\text { Score history } \\
\text { (VAM4) }\end{array}$ \\
\hline & (1) & (2) & (3) \\
\hline \multicolumn{4}{|l|}{ SD of teachers' estimated effects } \\
\hline Unadjusted for sampling error & 0.153 & 0.137 & 0.128 \\
\hline Adjusted for sampling error & 0.114 & 0.106 & 0.100 \\
\hline \multicolumn{4}{|c|}{ SD of bias if classroom assignments depend on predictions of true gains } \\
\hline \multicolumn{4}{|c|}{ Scenario } \\
\hline B Using observed achievement history & 0.039 & 0.005 & 0.000 \\
\hline C Using 2 independent achievement histories & 0.041 & 0.007 & 0.002 \\
\hline C Using 3 independent achievement histories & 0.041 & 0.008 & 0.003 \\
\hline D Using true achievement history & 0.043 & 0.010 & 0.004 \\
\hline E Using true history \& $\mathrm{W}$ variable $(\mathrm{f}=0.25)$ & 0.054 & 0.021 & 0.016 \\
\hline E Using true history \& $W$ variable $(f=0.5)$ & 0.065 & 0.033 & 0.028 \\
\hline E Using true history \& $W$ variable $(\mathrm{f}=1)$ & 0.087 & 0.056 & 0.051 \\
\hline F Using perfect information $(f=1.96)$ & 0.126 & 0.098 & 0.094 \\
\hline \multicolumn{4}{|c|}{ SD of bias if classroom assignments depend on predictions of observed gains } \\
\hline \multicolumn{4}{|c|}{ Scenario } \\
\hline B Using observed achievement history & 0.080 & 0.020 & 0.000 \\
\hline C Using 2 independent achievement histories & 0.111 & 0.043 & 0.019 \\
\hline C Using 3 independent achievement histories & 0.123 & 0.052 & 0.028 \\
\hline D Using true achievement history + obs. scores & 0.149 & 0.078 & 0.053 \\
\hline E Using true history \& $\mathrm{W}$ variable $(\mathrm{f}=0.25)$ & 0.155 & 0.084 & 0.059 \\
\hline E Using true history \& $W$ variable $(f=0.5)$ & 0.160 & 0.089 & 0.065 \\
\hline E Using true history \& $W$ variable $(f=1)$ & 0.171 & 0.101 & 0.076 \\
\hline F Using true gains $(f=1.96)$ plus observed scores & 0.191 & 0.123 & 0.099 \\
\hline
\end{tabular}

